\title{
Diabetes mellitus after liver transplantation: Another extrahepatic manifestation of hepatitis $\mathrm{C}$
}

\author{
Alnoor Ramji MD, Eric M Yoshida MD FRCPC
}

\begin{abstract}
ARTICLE
Bigam DL, Pennington JJ, Carpenter A, et al. Hepatitis Crelated cirrhosis: A predictor of diabetes after liver transplantation. Hepatology 2000;32(1):87-90.
\end{abstract}

\section{ARTICLE SUMMARY}

The aim of this study was to determine whether the prevalence of post-transplant diabetes mellitus (PTDM) was higher in liver transplant recipients infected with hepatitis $\mathrm{C}$ virus (HCV). A retrospective review of 278 recipients with $\mathrm{HCV}$, hepatitis B virus (HBV) and cholestatic disease (primary biliary cirrhosis and primary sclerosing cholangitis) between 1986 and 1997 was performed. Pre-transplant diabetes was higher in the HCV group. Diabetes prevalence one year after transplantation was $37 \%$ in the HCV group, $15 \%$ in the HBV group and $5 \%$ in the cholestatic group. Multivariate analysis revealed $\mathrm{HCV}$ and pretransplantation diabetes as independent factors for PTDM at one and two years. Immunosuppression and ribavirin use, and rejection episodes were similar. Cumulative steroid dose was lower in the HCV group. Survival was similar in patients with and without post-transplant diabetes.

\section{COMMENTARY}

There has been increasing evidence of a higher prevalence of diabetes mellitus in patients with HCV liver disease. Several epidemiological studies (1-3) have reported increased diabetes mellitus in HCV patients and have correlated this with more severe liver disease $(1,2)$. Postulated mechanisms to link HCV and hyperglycemia include insulin resistance and hyperinsulinemia (4), direct viral effects on B cell function (2), and association of HCV with autoimmune disorders (5). Bigam et al also reported increased diabetes mellitus in $\mathrm{HCV}$ patients before transplantation.

Post-transplantation diabetes mellitus is usually attributed to the immunosuppressive regimen, notably tacrolimus (6-8).
Of interest, Bigam et al reported that patients who received liver transplants for HCV had a higher prevalence of de novo diabetes mellitus, up to five years after transplantation, with HCV being an independent factor predictive - a finding similarly reported by Knobler et al (9). Whereas Knobler et al (9) reported that the PTDM patients had increased rejection episodes, Bigam et al did not find this result. Moreover, Bigam et al reported that immunosuppression type, age and body mass index were not predictive of PTDM on multivariate analysis.

$\mathrm{HCV}$ appears to be independently associated with increased diabetes mellitus, even after transplantation when liver function is expected to be good. Due to the morbidity and mortality associated with hyperglycemia, HCV patients should be monitored and treated - both before and after liver transplantation.

\section{REFERENCES}

1. Mason AL, Lau JY, Hoang N, et al. Association of diabetes mellitus and chronic hepatitis C virus infection. Hepatology 1999;29:328-33.

2. Caronia S, Taylor K, Pagliaro L, et al. Further evidence for an association between non-insulin-dependant diabetes mellitus and chronic hepatitis C virus infection. Hepatology 1999;30:1059-63.

3. Zein NN, Abdulkarim AS, Weisner RH, et al. Prevalence of diabetes mellitus in patients with end-stage liver cirrhosis due to hepatitis C, alcohol, or cholestatic disease. J Hepatol 2000;32:209-17.

4. Prietto J, Alford FP, Dudley FJ, et al. The mechanism of the carbohydrate intolerance of cirrhosis. J Clin Endocrinol Metab 1980;51:1030-6.

5. Hadziyannis SJ. The spectrum of extrahepatic manifestations in hepatitis C virus infection. J Viral Hepat 1997:4:9-28.

6. European FK506 multicentre liver study group. Randomized controlled trial comparing tacrolimus (FK506) and cyclosporine in prevention of allograft rejection. Lancet 1994;344:423.

7. Krentz AJ, Dousset B, Mayer D, et al. Metabolic effects of cyclosporine A and FK506 in liver transplant recipients. Diabetes 1993;42:1753.

8. Krentz AJ, Dmitrewski J, Mayer D, et al. Postoperative glucose metabolism in liver transplant recipients: a two-year prospective randomized study of cyclosporine versus FK506. Transplantation 1994;57:1666.

9. Knobler H, Stagnaro-Green A, Wallenstein S, et al. Higher incidence of diabetes in liver transplant recipients with hepatitis C. J Clin Gastroenterol 1998;26:30-3.

10. Navasa M, Bustamante J, Marroni C, et al. Diabetes mellitus after liver transplantation: prevalence and predictive factors. J Hepatol 1996;25:64-71. 


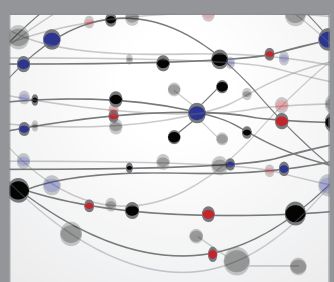

The Scientific World Journal
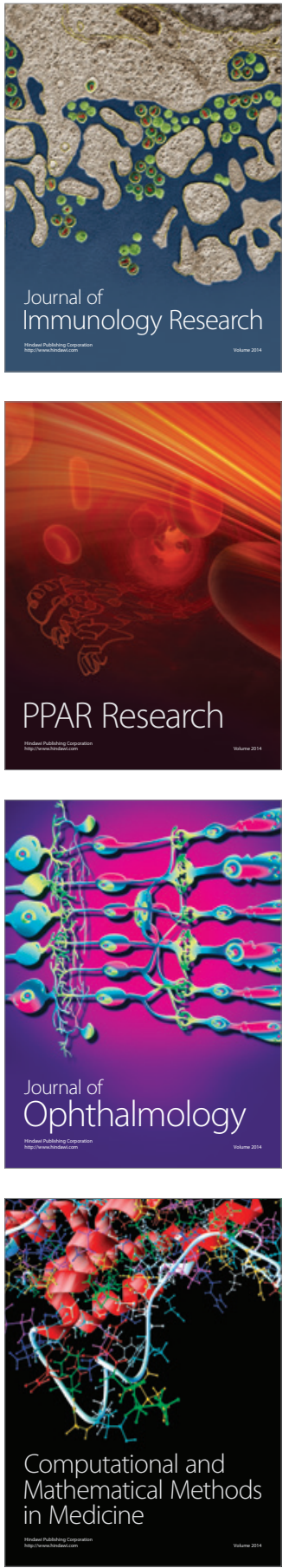

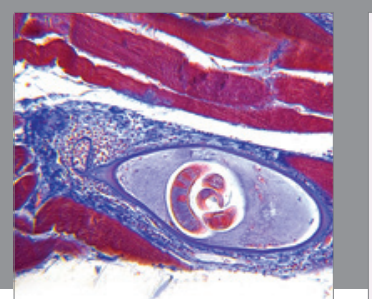

Gastroenterology Research and Practice

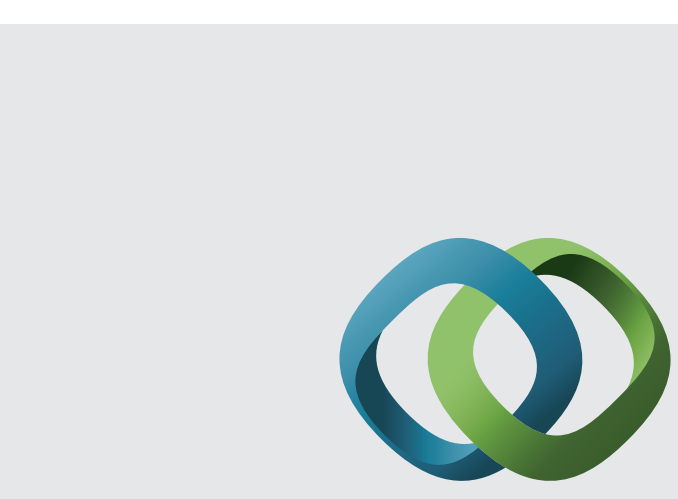

\section{Hindawi}

Submit your manuscripts at

http://www.hindawi.com
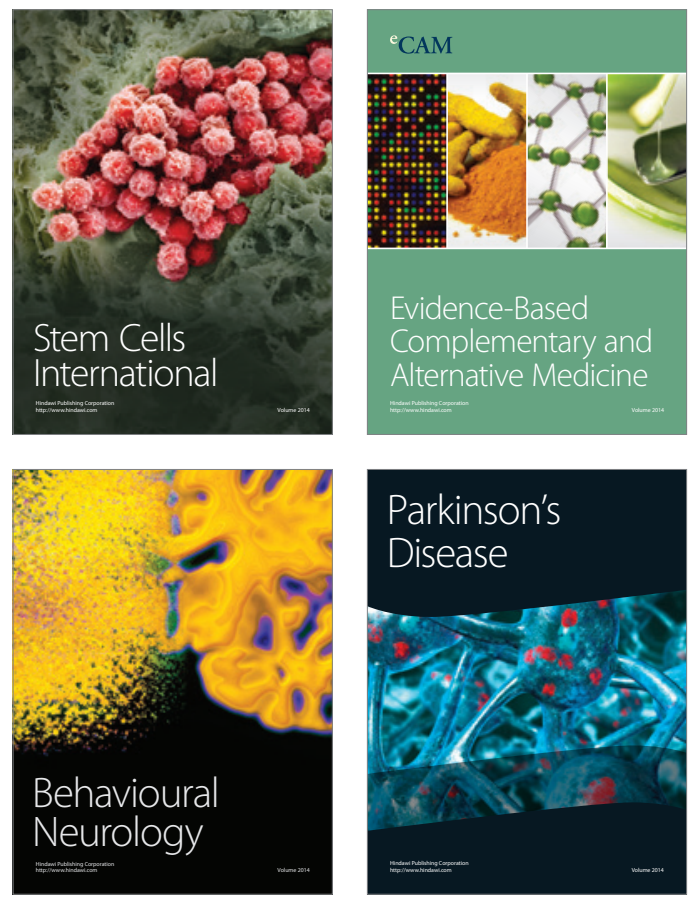
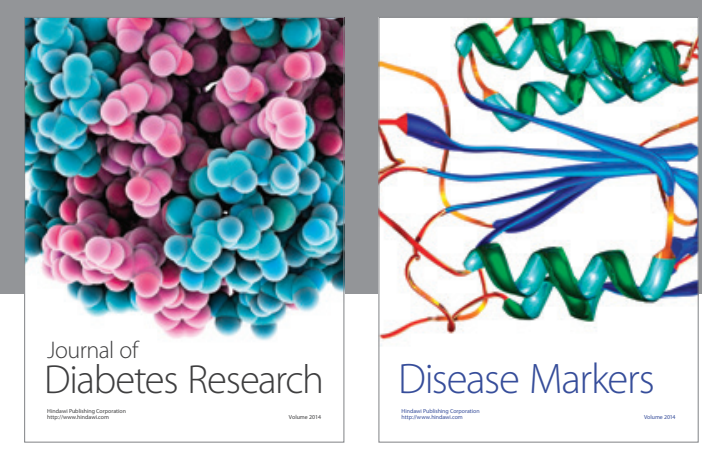

Disease Markers
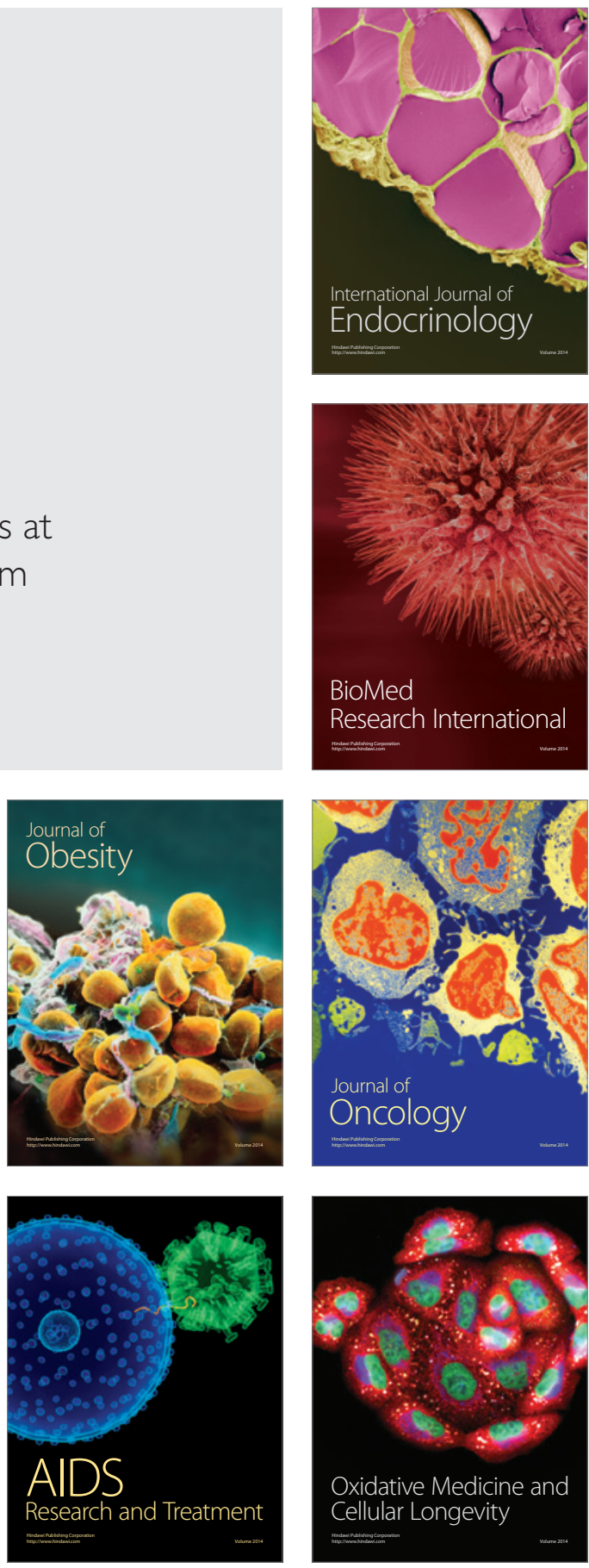